\title{
Posicionamentos contra Direitos Humanos: a realidade brasileira sob a perspectiva decolonial
}

\author{
Posicionamientos contra Derechos Humanos: la realidad \\ brasileña bajo la perspectiva descolonial
}

\section{Positions against Human Rights: The Brazilian reality under a decolonial perspective}

\author{
Matheus Mendanha CRuz \\ Investigador independente (Brasil) \\ matheusmcruz@live.com
}

Fecha de recepción: 13-01-2019

Fecha de aceptación: 04-05-2019

\section{RESUMO}

A reflexão proposta aqui tem como ponto de partida o ganho de espaço que a difusão de discurso contra os Direitos Humanos tem ganhado no Brasil. Tal reflexão torna-se central para a compreensão dos posicionamentos que são possíveis observar nas mídias que colocam a militância por Direitos Humanos como defensores de foras da lei, o que acaba por rebaixar, frente ao próprio sentimento de humanidade, o acusado por crimes e, consequentemente, o militante. Além desse aspecto o presente trabalho aponta para, baseado em conceitos como Cultura Histórica e Cultura Política, a dinâmica das ideias acerca do tema na sociedade brasileira. Dentro desse processo a ciência da história permite a reflexão sobre a utilização do passado, experiência, para a geração de sentido que orienta o posicionamento no presente. A conclusão a que chegou-se foi de que tais discursos contra os Direitos Humanos e, consequentemente, contra a Democracia são consequências da construção colonial do Brasil.

Palavras-chave: Modernidade, Direitos Humanos, Democracia, Cultura Histórica, Modernidade/Colonialidade.

Topônimos: Brasil

Período: século XXI

\section{RESUMEN}

La reflexión propuesta tiene como punto de partida la ganancia de espacio que la difusión del discurso contra los Derechos Humanos ha ganado en el Brasil actual. Esta reflexión se convierte en central para la comprensión de los posicionamientos de los medios que colocan a la militancia 
pro derechos humanos como defensores fuera de la ley, lo que acaba por rebajar, frente al propio sentimiento de humanidad, el acusado por crímenes y, en consecuencia, el militante. Además de este aspecto, el presente trabajo se basa en conceptos como Cultura Histórica y Cultura Política para explicar la dinámica de las ideas acerca de este tema en la sociedad brasileña. Dentro de ese proceso, la ciencia de la historia permite la reflexión sobre la utilización del pasado, experiencia que da sentido y orienta el posicionamiento en el presente. La conclusión es que tales discursos contra los Derechos Humanos y consecuentemente, contra la Democracia, son consecuencia de la construcción colonial de Brasil.

Palabras clave: Modernidad, Derechos humanos, democracia, Cultura Histórica, Modernidad /colonialidad.

Topónimos: Brasil

Período: siglo XXI

\section{ABSTRACT}

The starting point of the reflection proposed here is the increasing diffusion of the discourse against Human Rights in present-day Brazil. This reflection is central in order to understand the stance adopted by the media that situate pro-human rights activists outside the law. The diffusion of these ideas devalues accusations against crimes and consequently undermines the value of the allegations and arguments voiced by defenders of human rights. In addition to this aspect, this paper, on the basis of concepts such as Historical and Political Culture, explains the dynamics of ideas visà-vis this theme in Brazilian society. Within this process, the science of history allows for reflexion on the use of the past, experience that lends sense to and orientates the stance taken today. The conclusion is that this discourse against human rights and, consequently, against democracy, is a consequence of the colonial construction of Brazil.

Key words: Modernity, Human Rights, Democracy, Historical Culture, Modernity/Coloniality Place names: Brazil

Period: 21st century

\section{INTRODUÇÃO}

É possível perceber que em pouco tempo o discurso que profere sentenças como: Bandido bom é bandido morto!; Direitos Humanos para humanos direitos!; tem crescido e se avolumado nas redes sociais e nos posicionamentos políticos de representantes eleitos democraticamente. Um dos exemplos recentes são as postagens que, de certa forma, comemoram a morte da vereadora do Rio de Janeiro Marielle Franco e a acusam de ser uma das culpadas da violência na cidade carioca por estar "engajada com bandidos"1, afirmam que ela foi "morta por bandidos que ela defendia"2.

Perceber essa relação e assistir a manifestações que culpam as próprias vítimas pelo seu destino trágico torna possível, até mesmo necessário, refletir sobre os posicionamentos e as visões que a nossa sociedade tem tido acerca do estado político e de segurança no

1 Essa acusação foi feita pela desembargadora do Tribunal de Justiça do Rio de Janeiro (TJ-RJ) Marilia Castro Neves em uma rede social. Disponível em: https://oglobo.globo.com/rio/desembargadora-acusamarielle-franco-de-engajamento-com-bandidos-22500122 (Consulta: 17-03-2018).

2 Matéria que visa acusar a vereadora em questão de ser defensora de bandido e acabar pagando com a própria vida, além de apontar a esquerda de utilizar a morte de Marielle como fato político para minar a intervenção no Rio de Janeiro. Disponível em: https://www.jorgeroriz.com/marielle-nao-virou-santa-porquemorreu-ela-defendia-o-direito-dos-bandidos/ (Consulta: 17-03-2018). 
Brasil. Não é só o crescimento desse discurso de ódio, mas a notoriedade e o espaço que ele tem conquistado nos debates políticos atuais tem demonstrado o quanto existe uma resistência ao que foi construído e produzido pela modernidade ${ }^{3}$.

A eleição de Jair Bolsonaro também demonstra o crescimento de discursos contra Direitos Humanos e que se afastam de pilares que sustentam a Democracia. Uma vez que o presidente eleito durante a sua carreira política tem se colocado de forma clara na defesa de medidas como a redução da maior idade penal, castração química para estupradores, dentre outras, além de defender a ditadura imposta no Brasil em 1964.

A fala de Heller proferida nas Primeras Jornadas Latinoamericanas de Enseñanza de la Historia 4 realizada em Outubro de 2017 em Buenos Aires, Argentina sugeria colocar os Direitos Humanos como fator central para perceber as tensões e as tendências autoritárias que tem crescido pelo mundo, exemplos: forte candidatura de Le Pen; vitória de Trump; eleição de Bolsonaro; chegada ao congresso da extrema direita alemã.

É frente a esse panorama nacional e mundial, junto a proposta de Heller, que apresentamos o texto a seguir, buscando lançar alguns apontamentos teóricos acerca da relação dos conceitos de Direitos Humanos com a sociedade brasileira atual.

\section{CULTURA HISTÓRICA}

A formação das opiniões políticas perpassa pelas suas vivências em vários âmbitos, como igreja, família, partidos políticos, sindicatos, tribos urbanas, etc. Além desses ambientes também formam o posicionamento dos sujeitos os produtos culturais que ele consome, como músicas, filmes, peças teatrais, literatura, dentre outros.

Esse processo de formação de opinião é conceituado por Cultura Histórica. Ou seja, Cultura Histórica é o meio em que o sujeito está inserido e que acaba por formar e ser formado pela sua presença ali. A caracterização de histórica vem porque toda essa formação ocorre através da geração de sentido e esta acontece através da reorganização do passado 5 .

Antes de prosseguirmos com a discussão acerca de como a Cultura Histórica influencia o cotidiano e a formação de opinião gostaríamos de esclarecer as diferenças encontradas na literatura acerca desse conceito para que possa clarificar ao leitor ao que estamos nos referindo quando utilizamos o termo.

\subsection{Conceitos de Cultura Histórica \\ Elio Chaves Flores (2007: 95) coloca Cultura Histórica como:}

[...] os enraizamentos do pensar historicamente que estão aquém e além do campo da historiografia e do cânone historiográfico. Trata-se da intersecção entre a história científica, habilitada no mundo dos profissionais como historiografia, dado que se trata de um saber profissionalmente adquirido, e a história sem historiadores, feita, apropriada e difundida por uma plêiade de intelectuais, ativistas, editores, cineastas, documentaristas, produtores culturais, memorialistas e artistas que disponibilizam um saber histórico difuso através de suportes impressos, audiovisuais e orais.

3 Esse aspecto da Modernidade será mais problematizado mais à frente, pensando a relação do Brasil, país latino americano, e as ideias que começam a ser construídas no final do século XV.

4 O título da comunicação foi Progreso, regresión y derechos humanos e foi um dos motores para as reflexões aqui apresentadas.

5 Exploraremos o que é formação de sentido e como esse processo ocorre mais à frente. 
E é a essa conceituação de Flores que acataremos no decorrer do trabalho. Essa escolha ocorre por entendermos que essa conceituação do termo possibilita uma amplitude maior para a sua utilização, dando conta da formação e dinâmica do conhecimento histórico dentro da sociedade.

Entretanto utilizaremos para questões de aprofundamentos no próprio conceito de Consciência História as discussões e propostas feitas por Rüsen. Para este autor Cultura Histórica também tem essa relação entre o produzido pelos meios historiográficos e o produzido fora do mesmo, sendo ela capaz de viabilizar a interpretação do passado para poder orientar o presente (Rüsen, 2015: 217).

Essa viabilidade ocorre porque é através da Cultura Histórica que compreendemos as informações do passado e sobre o passado, além de ser através dela que conseguimos levar para a vida prática e cotidiana as nossas interpretações.

Se, por um lado, é a Cultura Histórica que viabiliza a interpretação quem a faz a Consciência Histórica. No processo de sua vida prática, os seres humanos necessitam estabelecer sentido para todos os aspectos de sua vida (relações sociais, relações com o sobrenatural, interpretação e produção de si mesmo no contexto da coletividade, relações com o que já passou e com o que está por vir etc.). A consciência histórica é um dos processos de produção de sentido fundamentais para os sujeitos em seus respectivos cotidianos.

\subsection{Cultura Política}

Sendo a Consciência Histórica a responsável por localizar temporalmente o sujeito e a Cultura Histórica a dinâmica de construção e difusão acerca do passado, é possível, para melhor compreensão do fenômeno a ser estudado, utilizar outros conceitos que somam ao arcabouço interpretativo.

Cultura História é um conceito amplo que é formado por vários outros, por exemplo: Cultura Historiográfica, Cultura de Massas, Cultura Política, etc. Destacamos aqui o conceito de Cultura Política por ele dar suporte para compreendermos as tradições e tensões que marcam a sociedade brasileira atual, dando uma noção mais ampla para ajudar-nos a compreender o posicionamento político atualmente no Brasil.

Não é nosso interesse aqui fazer um histórico do conceito de Cultura Política, afinal isso já foi feito ligando esse conceito ao século XX, principalmente a nomes como Sirinelli e Berstein, sendo nas décadas de 1950 e 1960 a introdução desse conceito nos meios acadêmicos (Motta, 2009).

Como definição para Cultura Política concordamos com Motta (2009: 21) quando ele afirma que:

Conjunto de valores, tradições, práticas e representações políticas partilhado por determinado grupo humano, que expressa uma identidade coletiva e fornece leituras comuns do passado, assim como fornece inspiração para projetos políticos direcionados ao futuro.

É importante ainda destacar que quando tratamos desse conceito não ignoramos o fato de haver tensões dentro de uma sociedade que, ao mesmo tempo, que permitem falar de uma Cultura Política geral também nos faz ressaltar que existem disputas no interior do espaço nacional.

Motta (2018: 113) ressalta ainda que o conceito não "implica imaginar que todos os integrantes do grupo se comportem de modo uniforme, como se fossem movidos por uma força atávica. Os sujeitos não são peças inertes diante das estruturas sociais perenes".

Esse conceito de Cultura Política nos possibilita uma ferramenta para a análise das tradições brasileiras em relação à política, não apenas institucional, mas no próprio cotidia- 
no. A seguir gostaríamos de destacar alguns traços característicos dessa Cultura Política brasileira que julgamos úteis para compreender o meio que forma os jovens brasileiros de Ensino Médio.

O primeiro aspecto que gostaríamos de destacar é a cultura conciliatória por cima. Ou seja, corriqueiramente há acordos entre as elites e o resultado dessas negociações são colocadas de forma naturalizada para a maioria da população. Olhando para a história nacional é possível perceber o reflexo dessa cultura variadas vezes, sendo o fim do regime ditatorial em 1985 talvez um dos mais claros indicadores dessa tradição ${ }^{6}$. Motta (2018: 132) destaca que esse aspecto traz o prejuízo de não conseguirmos enfrentar de frente problemas como o de desigualdade social, principalmente o legado da escravidão.

Se ater a esse processo de Cultura Política nos possibilita compreender os motivos pelos quais existe preconceito no Brasil e explica ainda um outro aspecto cultural que é o autoritarismo. Chauí (1995: 77) coloca que "a ideologia autoritária, que naturaliza as desigualdades e exclusões socioeconômicas, vem exprimir-se no modo do funcionamento da política" e ela vai mais além afirmando que a sociedade brasileira é visceralmente autoritária (Chauí, 1995: 74).

Em Nostalgia Imperial Ricardo Salles (2013: 50) demonstra que o problema em torno da escravidão era exatamente a formação da sociedade brasileira, que era escravocrata, e sediava boa parte do poder de persuasão do discurso político oficial em subjugar escravos e grupos populares. Ele afirma que

[...] o patriarcalismo, o patrimonialismo, o elitismo e o favor compuseram uma ética que uniu a prática política institucional à prática social cotidiana; que ligava mecanismos de influência e poder local aos corredores dos palácios do governo central (Salles, 2013: 58-59).

Ainda um último aspecto da Cultura Política brasileira que destacaremos aqui é o da fragilidade democrática ${ }^{7}$. Essa fragilidade democrática pode ser evidenciada, como já afirmado anteriormente, através das sucessivas intervenções militares. Um conceito que nos clareia acerca desse aspecto cultural é o de Padrão Moderador.

Esse conceito de Padrão Moderador é proposto por Alfred Stepan (1975). Para o autor, os militares, principalmente o exército, assumiram o papel de moderar que era do imperador durante o período monárquico. Sendo assim, todas as vezes que havia alguma crise nos processos republicanos os militares intervinham e depois devolviam os poderes para os civis. Foi assim, por exemplo, em 1930, 1937, 1945, 1954 e 1961. Esse padrão só foi quebrado em 1964 quando a intervenção militar impôs a Ditadura que foi liderada pelos próprios militares.

Essa debilidade na democracia faz com que Nóbrega Jr. (2010: 75) aponte o regime que vivemos no Brasil como uma semidemocracia que não caminha para a superação desse estágio.

Essa tradição autoritária, racista ${ }^{8}$, patrimonialista e antidemocrática influencia de forma direta os posicionamentos na atualidade. Isso ocorre por que essas ideias e posturas são transmitidas no cotidiano, circulam no senso comum. Piadas racistas sobre a escravidão, a postura autoritária frente ao outro numa partida de futebol ou no trânsito, o jeitinho brasileiro, dentre outros exemplos, difundem e proliferam as tradições destacadas acima.

6 O texto de Arturi (2001) permite uma dimensão das negociações e das políticas de continuidades do fim da Ditadura Civil-Militar brasileira.

7 Motta (2018: 132) usa a expressão "precariedade da democracia política".

8 Wolkmer e Bravo (2016: 47) apontam que a "relação constituinte o sistema capitalista atual tem como premissa, portanto, o reconhecimento de que o racismo é um eixo estrutural da nossa ordem social". 
Com o exposto até aqui é possível perceber que a Cultura Política brasileira e a Cultura Histórica não demonstram proximidade com a Democracia e nem com os Direitos Humanos. Afirmamos isto pelas características ressaltadas anteriormente acerca da cultura política e sua ligação com a formação social escravocrata pela qual o Brasil passou. A Cultura Histórica acaba por trazer argumentos e formas que reforçam essa postura autoritária e racista que foi/é base para a constituição da sociedade brasileira.

\subsection{Formação Histórica e Cultura Histórica}

Como opção para a mudança da Cultura Histórica e, consequentemente, da Cultura Política apresentamos o conceito de Formação Histórica. No campo da História, para desenvolver essa opção, Rüsen (2015: 252) aponta que é preciso ensinar a pensar historicamente. Borries (2016: 177-178) explica que

[...] as pessoas podem saber um conjunto de datas (reinos, batalhas, tratados, invenções, etc.), sem serem aptas para narrar a história de alguma forma [...] eles podem ser aptos a narrar longas histórias sem criticismo e habilidades metodológicas. Em minha opinião, tais características falham para cumprir uma condição da "competência histórica.

Pensar historicamente remete a habilidade de construir estruturas narrativas acerca do passado e que acabam por gerar sentido no presente. Essa habilidade, ou competência, é construída através do processo de Formação Histórica ${ }^{9}$.

Rüsen (2010: 101) define Formação Histórica como "um modo de recepcionar o saber (histórico) e lidar com ele, de tomar posição quanto a ele", dessa forma "formação baseia-se no aprendizado e é, simultaneamente, um modo próprio de aprendizado" (Rüsen, 2010: 104).

Ou seja, Formação Histórica é o aprendizado de como ler o mundo historicamente, desenvolvendo competências para que essas leituras fiquem mais apuradas. Ela também é uma forma de aprendizado porque a partir do momento que começo a ler o mundo a minha volta de forma mais aberta e levando em conta o seu caráter diacrônico eu me abro para o mesmo que passa a me ensinar rompendo com preconceitos e dogmas antes tidos como imutáveis.

Lemos aqui formação histórica de forma muito próxima que lemos o conceito de Leitura de Mundo proposto por Paulo Freire (1989). Sendo assim entendemos que formar historicamente é possibilitar que o sujeito desenvolva competências que o permitam o máximo de autonomia para uma leitura do passado que leve em consideração os preceitos da ciência histórica.

Esse processo pode ocorrer de várias maneiras diferentes, por exemplo, através da participação em entidades de base, de canais do Youtube, da escola, dentre outros meios que são constituintes e constituídos pela Cultura Histórica. Consequentemente a partir do processo de amadurecimento do pensamento histórico ${ }^{10}$ esse sujeito passa a enxergar o mundo e a se enxergar no mundo de forma diferente, além de alterar a sua Cultura Histórica.

A partir dessa mudança de olhar sobre a realidade são construídas ${ }^{11}$ mais ferramentas para que se interprete e reinterprete o passado, gerando novos sentidos e novas perspec-

9 A Formação Histórica ocorre em todos os âmbitos da Cultura Histórica, ou seja, não se limita apenas aos muros da escola.

10 Aqui denominamos como pensamento histórico todo o pensamento que leva em consideração o passado.

11 Procuramos utilizar o verbo construir, pois compreendemos o processo educativo como efetivamente como uma construção em que sujeitos se auxiliam. Lembrando Paulo Freire (1996: 25), "quem ensina aprende ao ensinar e quem aprende ensina ao aprender". 
tivas de futuro. Essa reinterpretação do passado pode ser libertadora, porque ela pode ser canal de conscientização, por exemplo, das permanências da escravidão ainda hoje.

Motta (2018: 132) afirma que não é impossível de mudar a Cultura Política. É pensando na possibilidade de mudanças e escolhas que a formação histórica se torna essencial para que o jovem se coloque como sujeito no seu cotidiano, percebendo e compreendendo as dinâmicas que o cercam.

Quando o sujeito compreende e respeita a diferença, isso possibilita um avanço rumo ao fortalecimento dos Direitos Humanos. Quando se falta essa leitura histórica da construção da sociedade brasileira aumenta-se o limbo entre a organização autoritária que vivemos atualmente e a modificação dessa organização para mais profundamente democrática.

\section{MODERNIDADE}

Ao olhar para o panorama feito acima acerca da Cultura Política é possível liga-lo ao processo de colonização da América a partir do século XVI. Ou seja, é a partir da modernidade que começa a se construir historicamente e politicamente uma tradição racista, autoritária e segregadora que ainda vigora no Brasil.

Desta forma, o conceito de Modernidade torna-se bastante caro às nossas reflexões, por dois motivos: Direitos Humanos e Democracia são conceitos relacionados ao surgimento desse período; o processo de construção da Cultura Histórica do Brasil também tem sua gênese na construção da modernidade.

Sendo assim, primeiro trabalharemos acerca da construção da ideia de Modernidade e, depois, com a relação da Modernidade com os conceitos de Democracia e Direitos Humanos.

\subsection{Construção da ideia de Modernidade}

Para compreendermos o que é a Modernidade nós utilizaremos as referências do grupo Modernidade/Colonialidade ${ }^{12}$. Esse grupo é formado por pensadores que procuram construir uma epistemologia a partir do sul global. Ou seja, pensar, no caso específico a América Latina, sem buscar o amparo das ephistemes europeias, construídas no e para o contexto europeu.

Dussel (1993: 50), um dos autores do M/C, coloca o surgimento da Modernidade nas expansões marítimas e a mudança de centro do Mar Mediterrâneo para o Oceano Atlântico. Já Giddens (1991: 8), por exemplo, coloca o surgimento da Modernidade ligado ao Iluminismo e Renascimento, datando assim do século XVII.

Concordamos aqui com Dussel, porque é esse processo de mudança no século XV e XVI que coloca a Europa como centro geopolítico do mundo ${ }^{13}$. É o processo de colonização que possibilita a difusão para a América, Ásia e África dos modos culturais dos europeus e dá início à Globalização. Além de ser nesse período que começa a construir-se a ideia do outro, que é bestializado e ridicularizado, em oposição ao europeu civilizado e evoluído. Afinal, não é possível pensar a Modernidade sem a Colonialidade (Mignolo, 2005: 37).

Dussel (2016: 58-59) divide a Modernidade em pelo menos três momentos: primeira modernidade, que é a modernidade ibérica "mercantil, pré-burguesa, humanista" (Dussel, 2016: 59); a segunda modernidade que inaugura-se com um desenvolvimento burguês das Províncias Unidas dos Países Baixos; e por fim, a modernidade inglesa e francesa que

12 Para não ficar repetitivo utilizarei das próximas vezes que me referir ao Grupo Modernidade/Colonialidade a sigla $\mathrm{M} / \mathrm{C}$.

13 Isso porque antes do século XV e XVI a Europa tinha uma participação marginal na dinâmica de comércio que perpassava norte da África, Ásia e Europa, sendo o principal centro a China (Mignolo, 2005: 37). 
expande o modelo anterior e lança base ao Iluminismo e a Revolução Industrial, que são a plenitude desse processo moderno.

Adotando essa divisão proposta por Dussel percebemos que Giddens ${ }^{14}$ admite como Modernidade apenas a última etapa e isso se deve a uma tradição que pertence ao Mito da Modernidade que coloca, mesmo estando na Europa, a Península Ibérica como periferia do processo central de modernização e desenvolvimento. Essa marginalização da Europa ibérica se dá porque a narrativa de constituição do continente está organizada em torno da tradição greco-romana e Portugal e Espanha surgem como Estados Modernos com forte influência do mundo mulçumano (Dussel, 1993: 44).

Esse Mito da Modernidade é classifica por Dussel como a defesa de que o processo moderno trouxe algum tipo de evolução e desenvolvimento e que espalhou essas ideias pelo mundo. Essa ideia teleológica está baseada na dialética, no contraponto e, consequentemente, na ideia de progresso (Hall, 2006: 14; Heller e Fehér, 1994: 53). Entretanto concordamos com Dussel (1993: 48) quando ele afirma que, na verdade, "Modernidade é a justificação de uma práxis irracional de violência"15.

Essa violência está exposta no processo de colonização e também, mais tarde, no imperialismo. É nesse berço de violências que o Brasil vai sendo construído, suas bases identitárias estão voltadas a um processo que camufla a sua violência velada. É com essa tradição que é formada a Cultura Histórica que incide sobre a juventude atualmente.

A questão que se coloca para a reflexão é: como um processo que cria a ideia de Direitos Humanos e de Democracia moderna ${ }^{16}$, que tem como um dos seus pilares a emancipação ${ }^{17}$ social (Santos, 1989: 3) pode ser violento e irracional?

A resposta para o aparente paradoxo está em compreender o que Boaventura de Souza Santos denomina de Pensamento Abismal. Compreendendo essa estrutura narrativa que coloca no centro a Europa, mais especificamente as potências imperialistas do século XIX e XX, e os EUA, como potência imperialista também, é possível adotar o conceito de Pensamento Abismal. Santos (2010: 11) afirma que "o pensamento ocidental moderno é um pensamento abismal. Este consiste em um sistema de distinções visíveis e invisíveis, as invisíveis constituem o fundamento para as visíveis" ${ }^{18}$.

Essa distinção se efetiva como se houvesse uma linha que dividisse, ficando de um lado o existente e do outro o não existente, o moderno e desenvolvido contra o em estado de natureza. Ou seja, dentro dessa lógica de pensamento, se a América é o lugar do nãoexistente e do selvagem não há porque as ideias emancipatórias da Modernidade valerem para ela, afinal ela seria pré-moderna.

São exemplos claros dessa lógica de pensamento a Constituição de Cádiz e a Revolução do Porto ${ }^{19}$. Ambos os movimentos de caráter liberal, entretanto defendiam uma

14 Outro autor que deixa claro esse posicionamento de forma menos direta é Hobsbawm (1996: 9-10) quando afirma que a Revolução Industrial inglesa lançou as bases econômicas e a Revolução Francesa as bases políticas do mundo moderno.

15 Tradução livre do autor: "Modernidad es justificatión de uma práxis irracional de violencia".

16 Trataremos mais à frente de Democracia Moderna e Direitos Humanos.

17 É importante destacar que os decoloniais não se utilizam da expressão emancipação, mas sim libertação. Isso se dá por entenderem que Emancipação é uma expressão ligada ao contexto europeu e refere-se aos próprios europeus.

18 Tradução livre do autor: "El pensamento occidental moderno es un pensamento abismal. Éste consiste en un sistema de distinciones visibles e invisibles, las invisibles constituyen el fundamento de las visibles".

19 Mesmo que o centro europeu da Modernidade afaste a Península Ibérica dele, esta ainda assim mantémse adotando um pensamento colonial, ainda mais enquanto mantinham as colônias americanas. 
recolonização da América. Estes exemplos citados acabam por demonstrar que os ideias liberais emancipatórios oriundos desse processo de modernidade limitam-se a própria Europa e atualmente ao eixo euro-americano ${ }^{20}$.

Outro exemplo que pode ser bastante evidente, mas que não diz respeito a América Latina especificamente é o da França na guerra contra a Argélia. Sendo os franceses os protagonistas das ideias liberais de liberdade e emancipação, segundo a narrativa de Modernidade defendida por Giddens e Hosbawm, como seria possível manter colônias e travar tal guerra?

Entendemos que a teoria do pensamento abismal proposta por Santos responde a esse questionamento e de explicar o motivo pelo qual a Modernidade mesmo trazendo em seu bojo as ideias de liberdade é altamente violenta. Essa violência acaba por refletir diretamente no cotidiano atual latino-americano, mais especificamente no Brasil.

O esforço aqui de estabelecer a relação da América Latina com a Modernidade é central, pois compreendemos a América Latina como um lugar epistêmico que influencia e é influenciado pelas ideias de sujeitos e grupos sociais.

\subsection{Democracia Moderna}

A formação moderna do Brasil influencia a Cultura Histórica e esta acaba por influenciar a organização política e social do país. Desta forma, nos ateremos a fazer um panorama do conceito de Democracia para ficar mais claro as relações entre essa organização com as tensões da Cultura Política.

Tomamos o conceito de democracia como sendo inconcebível trabalha-lo vinculado apenas ao pleito eleitoral, relegando a centralidade do processo histórico que gera e se alimenta da tensão entre o modo de organização do Estado e a relação deste com a sociedade. Esse posicionamento, de caracterizar a democracia apenas pela questão eleitoral, é denominado Minimalista Procedural e defende basicamente que

[...] a democracia é um regime político: (a) que promove eleições competitivas livres e limpas para o Legislativo e o Executivo; (b) que pressupõe uma cidadania adulta abrangente; (c) que protege as liberdades civis e os direitos políticos; (d) no qual os governos eleitos de fato governam e os militares estão sob controle civil (Mainwaring, Brinks, \& Pérez-Liñán, 2001: 645).

O posicionamento minimalista se limita apenas, mesmo sem declarar, aos direitos civis, ou seja, aos direitos burgueses. Isso fica claro quando autores relacionam a democracia ao direito ao voto e às garantias de que haja opções, quantas possíveis, para essa eleição, mas não abrangem, para caracterizar como regime democrático, a segurança social e o respeito às discussões ambientais e feministas, por exemplo.

Entretanto é importante ressaltar que mesmo pensadores que se colocam como minimalistas procedurais não julgam a segurança social como fator indispensável para a democracia, pois confirmam que "níveis elevados de desigualdade trabalham contra a democracia" (Mainwaring, Brinks, \& Pérez-Liñán, 2001: 651).

Concordam com o posicionamento de que a democracia deva ser caracterizada não só pelos processos eleitorais Neres, Dombrowski e Silva (2016: 120) quando afirmam que "não basta o método ser democrático: é preciso saber qual o conteúdo que poderá estar sob deliberação" e Nóbrega Jr. (2010, p. 77) quando destaca que "eleições devem ser

20 Quando nos referimos a esse eixo estamos fazendo menção a América Anglo-saxônica e a Europa denominada ocidental. 
seguidas de observações a respeito das instituições coercitivas tais como as polícias, as Forças Armadas, o Ministério Público, o sistema de justiça criminal etc".

É chamado de substancial o posicionamento em que "os princípios democráticos regentes da organização social estão tangenciados pelos direitos fundamentais" (Tonet, 2016: 50). É a dentro dessa lógica que compreendemos o conceito de Democracia, sendo essa a baliza para a discussão a seguir.

Pensando dessa forma que adotamos com centralidade os Direitos Humanos, mas trazemos o conceito de Democracia junto. Afinal, uma sociedade que respeite e defenda os Direitos Humanos é uma sociedade democrática. Da mesma forma que, ao contrário, uma sociedade que nega os Direitos Humanos é uma sociedade com traços autoritários em sua dinâmica política e social.

Na América Latina não considerar os fatores sociais para caracterizar a Democracia esvazia o próprio termo e também impossibilita uma análise mais efetiva da dinâmica política da região e, consequentemente, do Brasil. Nogueira (2014: 459) faz uma análise da crise política pelo qual a América Latina vem passando, destacando o processo de hiperpolitização onde tudo se torna controverso e em disputa, ao mesmo tempo que há uma despolitização, pois há uma desconfiança dos políticos e instituições. Desta forma importa emitir opiniões e indignações mais do que discutir ideias e buscar consensos (Nogueira, 2014: 460).

Junto a essa hiperpolitização vazia também é preciso ter consciência de que a Democracia proposta pela Modernidade não se torna efetiva na América Latina e nem no Brasil. Afirmamos isso porque "se as eleições são livres e limpas, mas elegem um governo que não consegue controlar as principais arenas políticas porque os militares ou alguma força o fazem, então o governo não é uma democracia" (Mainwaring, Brinks, \& Pérez-Liñán, 2001: 650). No Brasil, por exemplo, temos um histórico de intervenções militares ou de pressões militares ao governo que tornam a democracia brasileira bastante frágil.

Com os conceitos de Democracia apresentados é possível notar que a Cultura Política do Brasil, como já afirmado anteriormente, não é democrática, pelo contrário, é marcada pelo autoritarismo. Perceber esse aspecto ligando-o a formação violenta e autoritária que o país teve com o processo da Modernidade amplia a para a compreensão do crescimento do posicionamento contrário aos Direitos Humanos.

\subsection{Direitos Humanos}

É possível, segundo Caio José (2005: 2), conceituar Direitos Humanos a partir de três grandes matrizes de pensamento filosófico: idealista; positivista e crítico-materialista. A idealista coloca que os Direitos Humanos seriam universais, imutáveis e inerentes ao ser humano. A positivista lançar seu foco ao ordenamento jurídico, desta forma são Direitos Humanos aquilo que está regulado em lei. Por fim, a crítico-materialista tem inspiração marxista e vê os Direitos Humanos como conquista histórica das lutas sociais.

Aqui adotamos o posicionamento crítico, por compreendermos que a dinâmica das conquistas dos Direitos Humanos, desde o nível local até o global, se dá nas tensões entre sujeitos e instituições. Não há Direitos Humanos sem conflitos, isso se dá porque, como o Brasil foi colonizado por nação europeia, "ficaram arraigadas e impressas em nosso ordenamento jurídico, as tendências, as percepções, os entendimentos, e os pré-julgamentos, excludentes da visão etnocêntrica europeia" (Ribeiro \& Sparemberger, 2004: 6).

A teoria crítica é marcada principalmente pela ideia de práxis como reflexão e ação transformadora em dada realidade. Ou seja, os Direitos Humanos passam a "fundamentar-se na própria práxis de libertação dos oprimidos", desta forma um posicionamento crítico tem que ir "além dos marcos emancipatórios da tradição moderna, essencialista, racionalista e eurocêntrica" (Wolkmer \& Bravo, 2016: 42-43). 
Sendo assim, a ideia de Direitos Humanos foi se consolidando ao longo da história em relação com a observância da dignidade humana de maneira universal (Ribeiro \& Sparemberger, 2004: 1). Entretanto o que ser percebe atualmente é que esses direitos "não estão mais centrados meramente em necessidades corporalizadas nos direitos individuais, mas inclui direitos sociais, econômicos, culturais, transindividuais, etc." (Wolkmer \& Bravo, 2016: 60).

Naliteratura encontram-se apontadas três gerações de direitos humanos. Se observarmos estas três gerações é possível notar que estas se relacionam intrinsicamente com as tensões democráticas e seus avanços. Num primeiro momento, a luta que fundou o que chamamos de modernidade foi por direitos civis e políticos, basicamente inspirada na busca da liberdade formal. Ou seja, essa primeira geração pode ser considerada de direitos individuais, estando muito ligado à ideologia burguesa que se sobrepõe a aristocracia europeia do período (José, 2005: 5); já a segunda geração de Direitos Humanos refere-se aos direitos coletivos e das lutas proletárias. Dessa forma, "materializa-se nos denominados direitos sociais, econômicos e culturais, fundados a partir da igualdade real. Entre esses direitos estão os direitos à saúde, à moradia, à educação (...)" (José, 2005: 6); a terceira geração dos Direitos Humanos aparece após a II Guerra Mundial e refere-se aos direitos culturais, pós-materialistas, anunciadores de uma proposta de modos de vida alternativos, relacionam-se com as lutas feministas, ecológicas, antirracista, anti-nucleares, etc. (Santos, 1989: 4).

A periodização apresentada acima em primeira, segunda e terceira geração de Direitos Humanos se baseia única e exclusivamente na Europa. É uma periodização tão eurocêntrica que torna muito difícil utiliza-la para discutir aspectos referentes a América Latina sem o mínimo de violência epistemológica.

Santos (1989: 10) afirma que nem mesmo faz sentido pensar essas gerações para Portugal e Espanha e creio que esta afirmação pode ser estendida ao Brasil e a América Latina. Ficamos presos ao colonialismo epistêmico de forma que nos violentamos para cabermos dentro de um quadro que não necessariamente nos permite ler os nossos objetos, dessa forma ignoramos partes da realidade e das próprias teorias para fazermos caber na nossa pesquisa. Essa crítica não ficou apenas para os estruturalistas, pois com a decadência dos grandes modelos de interpretação surgiram outros modelos que ergueram barreiras e que, muitas vezes, nos forçamos a aceitar invés de lançar um olhar mais apurado ao empírico.

Embora o que venha sendo divulgado com maior vultuosidade seja uma linha narrativa que coloca o eixo euro-americano como central para as políticas de Direitos Humanos no mundo, o que se comprova é que "os países latino-americanos foram os protagonistas da ideia de 'Direitos Humanos internacionais'” (Sikkink, 2015: 216).

Há indícios de preocupação com Direitos Humanos na América Latina ainda durante o período colonial. Sendo que no pós-guerra o consenso sobre a necessidade de se estabelecer leis internacionais para garantir esses direitos se fortaleceu em especial entre os latino-americanos, tendo em conta a onda de democratização e assunção de governos de centro-esquerda na década de 1940 (Sikkink, 2015: 217).

Esses indícios indicados no parágrafo anterior ainda estão baseados na lógica europeia do lluminismo e da intelectualidade. Wolkmer e Bravo (2016: 46) vão mais além e destacam que a narrativa que coloca nos século XVII e XVIII o nascimento da ideia de Direitos Humanos, ligando-a aos ideias burgueses ignora por completo, por exemplo, a luta por esses mesmos direitos que os indígenas travaram contra a dominação europeia na América.

Com os parágrafos acima foi possível perceber que a construção da ideia de Direitos Humanos e também da sua aplicação para em nível internacional tem grande participação latino-americana. Entretanto o que se vivencia nessa sub-região do globo é a ausência 
desses direitos no cotidiano. Kempf (1993) explica a dificuldade que europeus tem de compreender a vivência latino-americana, sendo um dos fatores para tal a falta de respeito aos Direitos Humanos na América Latina ${ }^{21}$. Ele chega a destacar que "torna-se inimaginável [para um europeu] entender o que significam conquistas como o abastecimento de produtos alimentícios básicos e alfabetização para a população" (Kempf, 1993: 197).

Embora o texto de Kempf seja de mais de vinte anos atrás o panorama não mudou significativamente. Ainda apresentamos no Brasil 11,8 milhões de analfabetos, cerca de $7,2 \%$ da população de 15 anos ou mais ${ }^{22}$. Cerca de 13 milhões de pessoas ainda vivem em pobreza extrema no país ${ }^{23}$.

\section{ANÁLISE DE DADOS EMPÍRICOS}

Para fortalecer a argumentação feita até aqui expomos dados de uma pesquisa de caráter quantitativo. Os dados aqui apresentados pertencem ao projeto Residente: observatório das relações entre jovens, política e história na América Latina ${ }^{24}$. O recorte que fizemos para o presente texto foi de estudantes de Ensino Médio, $1^{\circ}$ e $2^{\circ}$ ano, de uma escola pública no interior de Santa Catarina que responderam ao questionário no dia 26 de abril.

A coleta de dados desse projeto está ocorrendo em vários países da América Latina e tem como objetivo compreender a Cultura Histórica de jovens estudantes, além de pensar soluções e propostas para a área do Ensino de História.

A cidade onde ocorreu a coleta de dados é pequena, tem menos de 20.000 habitantes, localizada na região do Brasil com menor desigualdade social, medida pelo índice de GINI ${ }^{25}$, e no estado que está abaixo da média na taxa nacional, por 100 mil habitantes, de homicídios $^{26}$. Em conversas no cotidiano ${ }^{27}$ as pessoas aparentam relacionar a violência e criminalidade apenas às grandes cidades do Brasil, como Rio de Janeiro e São Paulo.

Os jovens foram avisados com antecedência para levarem seus celulares para escola no dia marcado. A aplicação foi feita na sala de vídeo da escola, onde os estudantes conectaram seus smartphones à rede da escola ou, caso estivesse sobrecarregada, à rede roteada pelo aplicador. Foi disponibilizado nos grupos de whattsapp o link para o formulário na plataforma da Google para que os estudantes pudessem responder. A aplicação ocorreu por turma e cada uma levou cerca de 45 min., tempo de uma aula, para responder às questões.

Como o instrumento é bastante amplo, separamos para a presente discussão apenas as respostas à questão com o seguinte enunciado: Os temas a seguir são sobre a vida social. marque o seu grau de concordância ou discordância com as afirmações abaixo.

21 Bartolomé Clavero é um dos autores que trabalha acerca do colonialismo nas constituições latinas, fato que se relacionar com o distancimetno dos direitos fundamentais. Ver Clavero (2017).

22 "Brasil ainda tem 11'8 milhões de analfabetos, segundo IBGE". Disponível em: https://oglobo.globo.com/ sociedade/educacao/brasil-ainda-tem-118-milhoes-de-analfabetos-segundo-ibge-22211755 (Consulta: 1812-2018).

23 "Cerca de 13 milhões ainda vivem em pobreza extrema no Brasil, diz IBGE". Disponível em: https:// www1.folha.uol.com.br/mercado/2017/12/1943549-cerca-de-13-milhoes-ainda-vivem-em-pobreza-extremano-brasil-diz-ibge.shtml (Consulta: 18-12-2018).

24 Esse é um projeto financiado pela Capes. O link a seguir é da explicação de Cerri sobre o que é o projeto citado. Disponível: https://www.youtube.com/watch?v=v0NwkE1-9FA\&t=2199s (Consulta: 01-05-2019).

25 São dados apresentados pelo IBGE (Instituto Brasileiro de Geografia e Estatística). Disponível em: https://biblioteca.ibge.gov.br/visualizacao/livros/liv101459.pdf (Consulta: 01-05-2019).

26 Dados apresentado pelo IPEA (Instituto de Pesquisa Econômica Aplicada). Disponível em: http://www. ipea.gov.br/atlasviolencia/download/9/atlas-2018 (Consulta: 01-05-2019).

27 Afirmamos isso, pois vivemos no município onde a coleta de dados foi feita. 
Abaixo segue os gráficos com as respostas dos estudantes, no título de cada gráfico está a frase frente à qual o jovem deveria posicionar-se. Importante destacar as opções de respostas eram discordo totalmente; discordo; nem concordo nem discordo; concordo; concordo totalmente; entretanto nenhum dos estudantes optou pela opção nem concordo nem discordo.

Gráfico1. Concordância ou discordância: Olho por olho, dente por dente

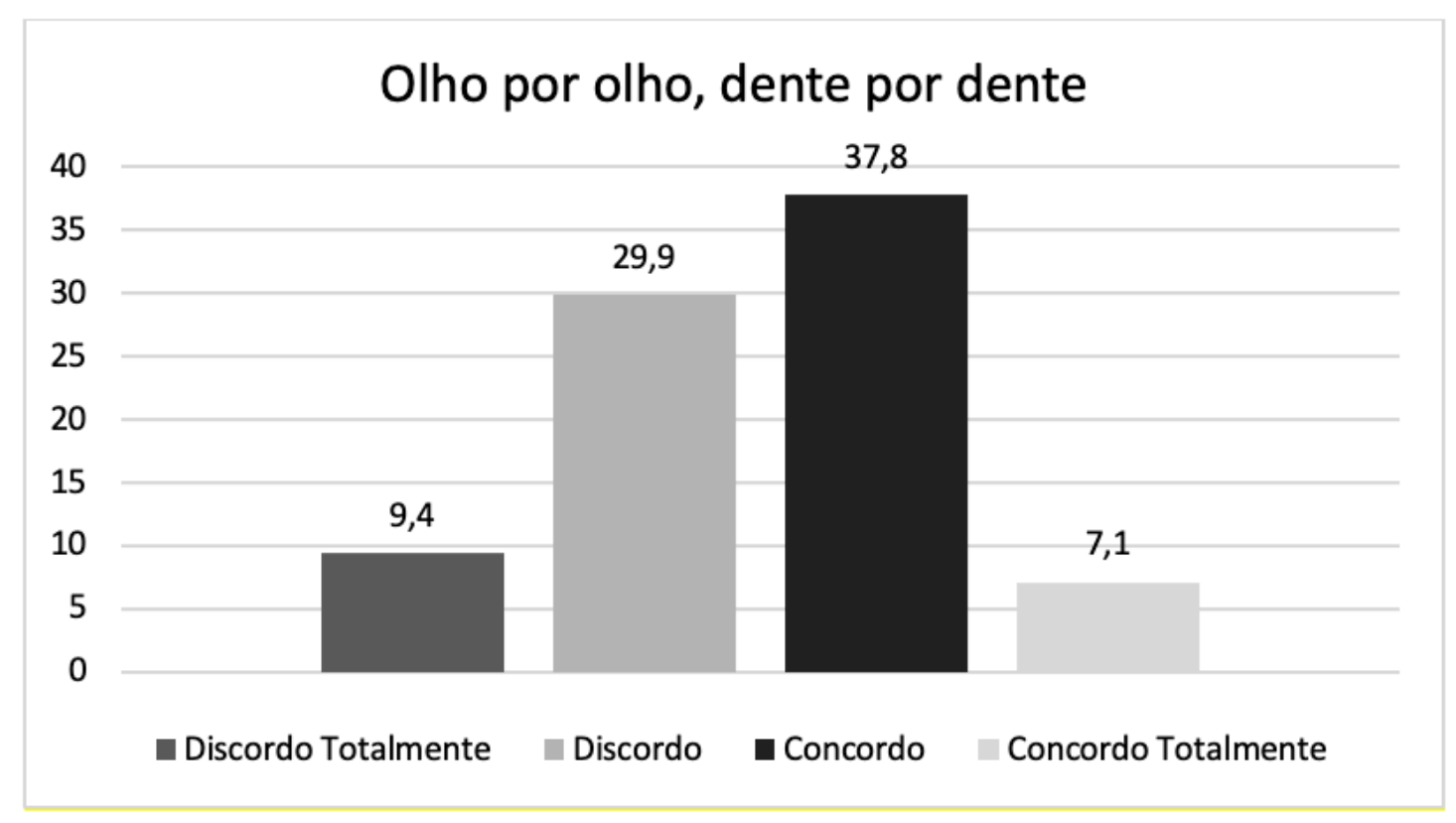

Fonte: Projeto Residente: os jovens e a História na América Latina

Gráfico 2. Concordância ou discordância: a pena de morte deveria existir para a maioria dos crimes hediondos

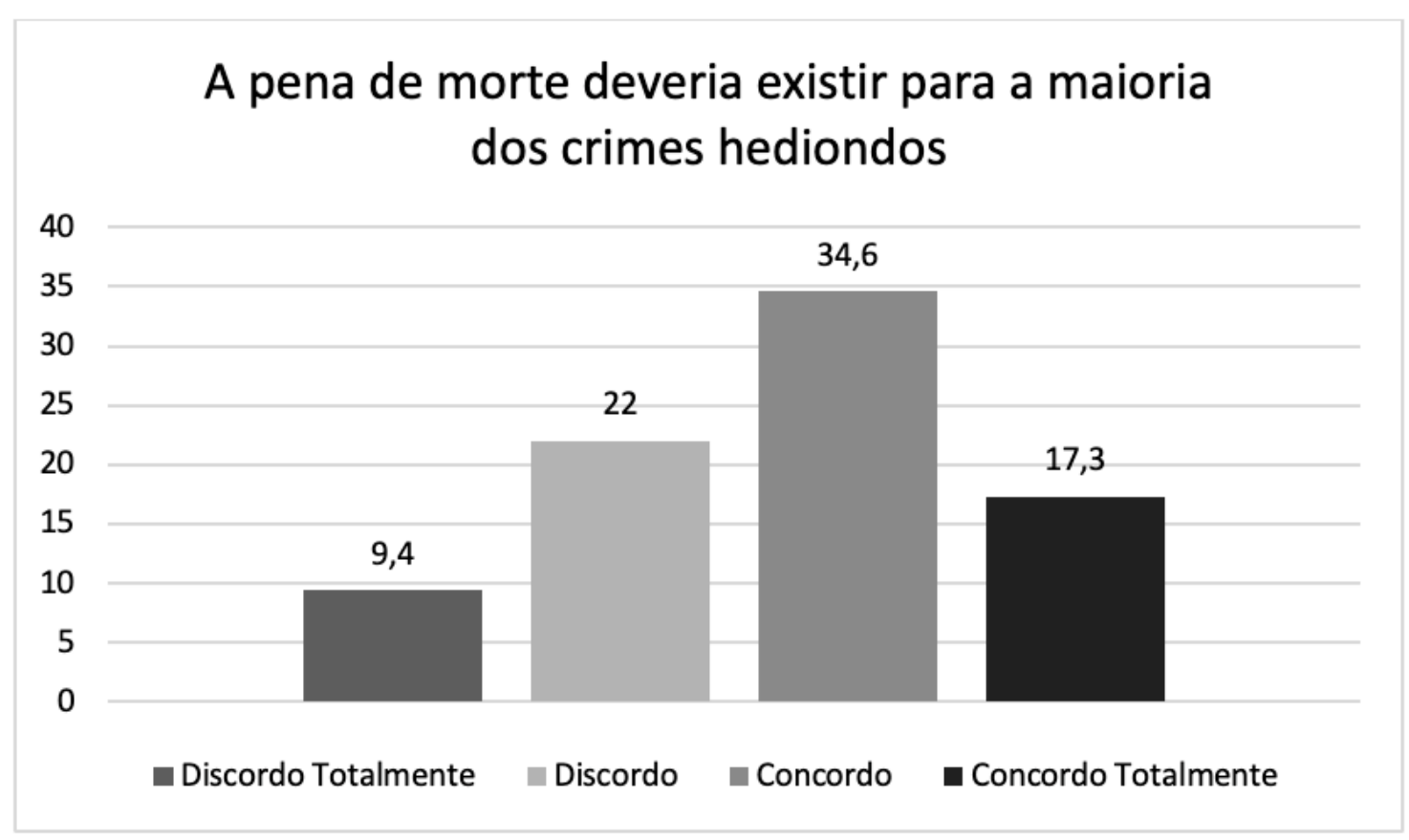

Fonte: Projeto Residente: os jovens e a História na América Latina 
Gráfico 3. Concordância ou discordância: é perda de tempo tentar reabilitar certos criminosos

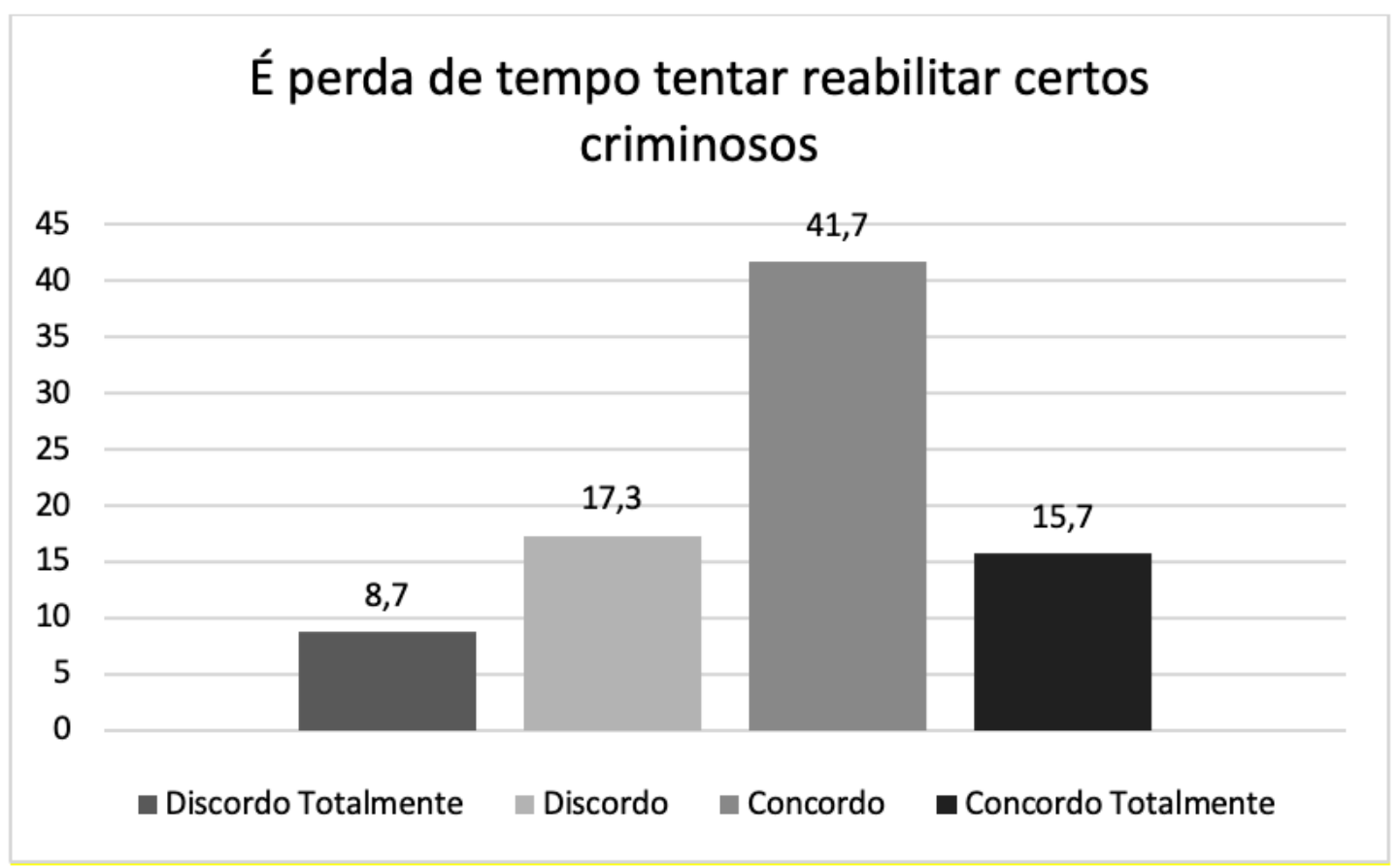

Fonte: Projeto Residente: os jovens e a História na América Latina

O primeiro gráfico demonstra as respostas frente ao princípio do código de Hamurabi. Pressupõem-se que os jovens tem conhecimento acerca dessa frase uma vez que tradicionalmente ela é estudada tanto no sexto ano do Ensino Fundamental como no início do primeiro ano do Ensino Médio. Embora o seu princípio seja antigo e bastante simples, os dados demonstram uma simpatia considerável pela ideia de retaliação.

Os dois últimos gráficos estão, de certa forma, interligados já que indicam a descrença na recuperação do sujeito que tenha cometido delitos. O gráfico 2 indica uma simpatia pela pena de morte e o gráfico 3 pode ser interpretado como o motivo para tal simpatia: não é possível reabilitar a maioria dos criminosos.

Embora Direitos Humanos não se resumam apenas ao tratamento de sujeitos que infligem as leis, utilizamos aqui esse fator para pensar o processo da Modernidade. Apontamos como principal motivo para esse afastamento da esperança de reabilitação de criminosos a falta de empatia. Como os jovens residem em uma região com uma desigualdade social menor que a do restante do país e num estado com uma taxa de homicídios abaixo da nacional é possível que a construção da ideia do outro seja bastante forte. Esse outro seria, dentro da lógica moderna, o bárbaro, o animalesco, o não-humano.

Jesse Souza (2017) nos auxilia a entender esse fenômeno quando indica que um brasileiro de classe média ele se enxerga como um europeu frente aos grupos sociais menos abastados, na régua capitalista. Ou seja, quando esses jovens apontam para a violência como recurso punitivo à crimes violentos muito possivelmente ele está pesando nesse outro construído e que se localiza longe do sujeito respondente.

Afirmamos isso porque, segundo o Mapa do Encarceramento (2015), a maior parte dos presos no Brasil são jovens entre 18 e 25 anos, com ensino fundamental incompleto, homens e negros. Desta forma, é possível relacionar esses dados com uma possível visão dos jovens respondentes do criminoso, sendo este justamente o jovem negro, pobre e sem 
estudo. Essa possibilidade é fortalecida porque a maioria esmagadora dos respondentes eram brancos ${ }^{28}$ e todos estão cursando o Ensino Médio.

Além da construção do outro, esses dados dão conta de demonstrar quão forte é no meio desses jovens a cultura política autoritária, onde a punição é mais importante que o processo de reeducação. Safatle (2016) indica, por exemplo, que o principal afeto que organiza as relações sociais no Brasil é o medo. Isso fica evidente quando em um período no Brasil onde há a um clima de violência (e de medo) as saídas retoma-se as propostas violentas, centralizadoras e autoritárias.

\section{CONSIDERAÇÕES FINAIS}

A ascensão de discursos que se colocam contra os Direitos Humanos no Brasil não é anti-moderno, pelo contrário. Quando se compreende que a Colonialidade e inerente à Modernidade e que vai além das amarras políticas, subalternizando identitária e epistemicamente torna-se possível ler a falta de Democracia no país como consequência direta do processo colonial.

Posicionamentos que criminalizam a pobreza são parte da construção violenta pelo qual a sociedade brasileira passou, entranhando esses pensamentos na Cultura Política nacional. Isso porque construiu-se uma identidade brasileira que se enxerga menor que o europeu, mas objetivando, de alguma maneira, se tornar europeu. Ou seja, o brasileiro vê-se como um em desenvolvimento, desta forma se percebe menor que o centro euro-americano quando comparado ao estrangeiro, mas quando olha para dentro do próprio país adota os posicionamentos racistas e violentos advindos da modernidade porque identifica como subalternizados apenas os pobres, negros, indígenas, etc.

Essa lógica é possível perceber quando se tem no Brasil o famoso complexo de vira-lata, mas, mesmo assim, há sentimento de repulsa ao pobre ${ }^{29}$, ou mesmo negros que são contra a política de cotas e afirmam que esta reforça o racismo.

É essa Cultura Histórica que permite a difusão de discursos de posicionamentos antidemocráticos, mas mesmo assim discursos legalistas. Esse aparente paradoxo se resolve quando o interpretamos como a ânsia de se perpetuar um discurso alinhado às ideias iluministas, mas nega-se a totalidade da população brasileira. Isso porque ainda se mantêm a visão de que a maior parte dos brasileiros é formado por bestializados que devem ser dominados e educados, pois não são capazes de escolherem seus próprios caminhos, por serem dominados pela ignorância e por não terem cultura ${ }^{30}$.

Não há espanto nem paradoxo no crescimento da difusão de posicionamentos anti-democráticos e contrários aos direitos fundamentais. A Cultura Histórica brasileira é formada sobre as bases do autoritarismo e do racismo, a Cultura Política continua colonizada quando defende governos centralizados e autoritários, mas aplaude a democracia de outros países, sempre EUA ou potências da Europa Ocidental.

Os dados poderiam indicar a negação da Modernidade, já que os jovens tem se colocado contra os processos de reeducação. Entretanto a leitura que fazemos é justamente da força da Modernidade, uma vez que a imagem gerada de si se coloca como superior ao outro, o que é o cerne da construção desse projeto moderno.

28 Foi possível perceber essas características durante a aplicação do questionário.

29 Ao escrever essas palavras lembrei-me de um jargão do personagem Caco Antibes do seriado Sai de Baixo que demonstra bem o sentimento da classe média e da elite brasileira: "Eu tenho horror a pobre!".

30 Ainda é essa a afirmação que ouve-se quanto a movimentos como o Hip-Hop, Funk, Reggae, Grafites, dentre outros. 
A proposta de mudança que se indica é a partir de uma leitura decolonial dos problemas enfrentados pela e na sociedade brasileira. É preciso descolonizar-se, pensar em saídas a partir do próprio país, levando em conta os mais variados segmentos e culturas que formam a dinâmica social brasílica. Dessa forma, afastando-se assim dos preconceitos e da dicotomia que coloca as tradições negras e indígenas, por exemplo, como menores e cheias de simpatias, em oposição a evoluída e científica tradição euro-americana.

\section{BIBLIOGRAFIA}

Arturi, C. S. (novembro de 2001): "O debate Teórico sobre mudança de regime político: o caso brasileiro", Revista de Sociologia e Política , 17, 11-31.

Ballestrin, L. (mai./ago. de 2013): "América Latina e o giro decolonial”, Revista Brasileira de Ciência Política, 11, 89-117.

Borries, B. V. (abr./jun. de 2016): "Competência do pensamento histórico, domínio de um panorama histórico ou conhecimento do cânone histórico", Educar em Revista, 60, 171-196.

Brasil (2015): Mapa do Encarceramento: os jovens do Brasil. Brasília, Presidência da República.

Cerri, L. F. (Inverno de 2001): "Os Conceitos de Consciência Histórica e os Desafios da Didática da História", Revista de História Reginonal, 6 (2), 93-112.

Chauí, M. (1995): "Cultura Política e Política Cultural”, Estudos Avançados, 9 (23), 71-84.

Clavero, B. (2017): "Constitucionalismo y colonialismo en las américas: el paradigma perdido en la historia constitucional", Revista de Historia del Derecho, 53, 23-39.

Cruz, M. M. (jan./jun. de 2018a): "Cultura Histórica e Função Social da escola: uma reflexão empírica com jovens de Ensino Médio", RELVA, 5 (1), 25-42.

Dussel, E. (jul./set. de 1993): "Europa, modernidad y eurocentrismo", Revista de Cultura Teológica, 4, 69-81.

- (Jan./Abr. de 2016): "Transmodernidade e interculturalidade: interpretação a partir da filosofia da libertação", Revista Sociedade e Estado, 31(1), 51-73.

Flores, E. C. (2007): "Dos Feitos e dos Ditos: História e Cultura Histórica", Sæculum - Revista de História, 16, 83-102.

Freire, P. (1989): A Importância do Ato de Ler: em três artigos que se completam. São Paulo, Autores Associados, Cortez (Coleção Polêmicas do Nosso Tempo; 4).

- (1996): Pedagogia da Autonomia: Saberes Necessários à Prática Educativa, São Paulo, Paz e Terra.

Giddens, A. (1991): As conseqüências da modernidade. São Paulo, UNESP.

Gramsci, A. (1991): Os Intelectuais e a Organização da Cultura, Rio de Janeiro, Editora Civilização Brasileira.

Hobsbawm, E. (1996): A Revolução Francesa, Rio de Janeiro, Paz e Terra.

José, C. J. (2005): "Dialética dos Direitos Humanos: da Modernidade à Pós-Modernidade", Revista da Faculdade de Direito UFPR, 43(0).

Kempf, W. (1993): "A luta pelos Direitos Humanos na América Latina: alguns problemas sobre sua percepção na Europa", Em H. Riquelme, Era de Névoas : direitos humanos, terrorismo de estado e saúde psicossocial na América Latina, São Paulo, PUC, 195199.

Le Goff, J. (1996): História e Memória. (B. L. al.), Trad. Campinas, Editora da UNICAMP.

Mainwaring, S., Brinks, D., \& Pérez-Liñán, A. (2001): "Classificando Regimes Políticos na América Latina, 1945-1999", DADOS-Revista de Ciências Sociais, 44(4), 645-687.

Mignolo, W. (2005): "A colonialidade de cabo a rabo: o hemisfério ocidental no horizonte conceitual da modernidade", em E. Lander (org.), A colonialidade do saber: eurocen- 
trismo e ciências sociais. Perspectivas latino-americanas, Buenos Aires, CLACSO, Consejo Latinoamericano de Ciencias Sociales, 35-54.

Motta, R. P. (2009): "Desafios e possibilidades na apropriação de cultura política pela historiografia", em Culturas políticas na história: novos estudos, Belo Horizonte, Argvmentvm, 13-37.

- (jan./mar. de 2018): "Cultura política e ditadura: um debate teórico e historiográfico", Tempo \& Argumento, 10(23), 109-137.

Neres, G. M., Dombrowski, O., \& Silva, V. S. (jan./jun. de 2016): "A construção do conceito moderno de democracia: versão inicial de um projeto de pesquisa", Tempo da Ciência, 23(45), 116-134.

Nôbrega Jr, J. M. (jan./abr. de 2010): "A Semidemocracia Brasileira: autoritarismo ou democracia?", Sociologias, 12(23), 74-141.

Nogueira, M. A. (2014): "Democracia, ativismo e modernidade radicalizada na América Latina", Polis-revista latinoamericana, 13(37), 457-472.

Ribeiro, B. C., \& Sparemberger, R. F. (2004): "Os Direitos Humanos e as perspectivas decoloniais: a condição do sujeito subalterno no Brasil", Amicus Curiae, 1(1).

Rüsen, J. (2010): História Viva: teoria da História. Formas e funções do conhecimento histórico. (E. d. MARTINS, Trad.) Brasília, UnB.

- (2015): Teoria da História: Uma teoria da história como ciência. (E. C. Martins, Trad.) Curitiba, Editora UFPR.

Saddi, R. (2010): "Didática da História como sub-disciplina da Ciência Histórica", História \& Ensino, 16(1), 61-80.

Safatle, V. (2016): Circuito dos Afetos: Corpos Políticos, desamparo e o fim do indivíduo, Autêntica.

Salles, R. (2013): Nostalgia Imperial: Escravidão e Formação da identidade nacional no Brasil do Segundo Reinado, Rio de Janeiro, Ponteio.

Santos, B. d. (Junho de 1989): "Os Direitos Humanos na Pós-Moderniade", Oficina do CES, 10.

- (2010): Para descolonizar Occidente: más alla del pensamiento abismal, Buenos Aires, Consejo Latinoamericano de Ciencias Sociales CLACSO; Prometeo Libros.

Sikkink, K. (2015): "Protagonismo da América Latina em Direitos Humanos", SUR 22, 12(22), 215-227.

Silva, K. V., \& Silva, M. H. (2009b): "Democracia", em Dicionário de Conceitos Históricos, São Paulo, Editora Contexto, pp. 89-93.

Silva, M. M., Fuhrmeister, A. V., Brum, A. F., Costa, F., Rosito, G., Pizutti, L. T., \& Leite, S. S. (abril de 2003): "A consciência: algumas concepções atuais sobre sua natureza, função e base neuroanatômica", R. Psiquiatr, 25(1), 52-64.

Silva, T. T. (2010): Documentos de identidade: uma introdução às teorias do currículo, Belo Horizonte, Autêntica.

Souza, J. (2017): A elite do atraso: da escravidão à Lava Jato, Rio de Janeiro, Leya.

Stepan, A. (1975): Os Militares na Política: Mudanças de Padrões na vida Brasileira, São Cristóvão - RJ, Editora Artenova.

Tonet, F. (maio de 2016): "Os direitos fundamentais e o conceito de democracia", REDES-Revista Eletrônica Direito e Sociedade, 4(1), 45-61.

Wolkmer, A. C., \& Bravo, E. E. (2016): "Horizontes para se repensar os Direitos Humanos numa perspectiva libertadora", em J. D. Leal \& L. M. Fagundes, Direitos Humanos na América Latina, Curitiba, Multideia, pp. 39-64. 